\title{
SOCIAL MEDIA AND ITS IMPACT ON USER BEHAVIOR - A METHODOLOGICAL AND THEMATIC REVIEW
}

\author{
Sana Singh \\ M.B.A. Student, Symbiosis Institute of Management Studies (SIMS) \\ Symbiosis International (Deemed University) (SIU), Pune, India \\ Malvika Kumar \\ M.B.A. Student, Symbiosis Institute of Management Studies (SIMS) \\ Symbiosis International (Deemed University) (SIU), Pune, India
}

\section{Aakanksha Rawat}

M.B.A. Student, Symbiosis Institute of Management Studies (SIMS)

Symbiosis International (Deemed University) (SIU), Pune, India

\section{Ritvik Khosla}

M.B.A. Student, Symbiosis Institute of Management Studies (SIMS)

Symbiosis International (Deemed University) (SIU), Pune, India

\section{Smita Mehendale}

Assistant Professor, Symbiosis Institute of Management Studies (SIMS) Symbiosis International (Deemed University) (SIU), Pune, India

\begin{abstract}
Social Media has invaded all walks of life including the way we consume content. The literature is rich with research on various aspects of social media and its impact on user behavior, organisations, and the society. This systematic literature review has been done to highlight the key themes and methodologies in extant literature for social media and its impact on user behavior. With 61 journal articles as the base of this review, 4 main research themes emerged, namely consumer motivation, effects of the platform format, content type, and the inverse impact of user behavior on the platforms. On exploration of the methodologies used in the relevant literature, a variety of approaches i.e. qualitative, quantitative, mixed, and non-empirical studies have been used to analyze social media usage and its impact on user behavior. Based on the methodological and thematic review, recommendations are provided for future research.
\end{abstract}

Keywords: User Behavior, Social Media, Online Consumer Behavior, User Engagement, Methodological Review, Systematic Literature Review, Thematic Review

\section{INTRODUCTION}

In the last two decades, digital consumption has drastically changed with the invasion of social media in all walks of our lives. Businesses and academics have been intrigued with the wide application of social media and the way it has transformed our lives. Extensive research has been conducted to understand its ever increasing usage and impact on consumer behavior. The motivation for conducting this systematic literature review is the existing gap in literature for a comprehensive study on social media and consumer behavior. This study brings together vast existing literature on social media and changing patterns of media consumption by consumers. These changes have also led organizations to think creatively on the use of social media to engage their customers. This study brings together the evolution of the various social media platforms along with factors leading to their preferences and how organizations use these platforms to enhance customer engagement. The study also suggests future direction for research in social media.

With the integration of social media into our lives, the need to share, engage, and entertain has increased exponentially. The possibility of mobile internet usage has further amplified the use of social media as the undeniable 
source for all forms of news and information available.

Social media has also become an enabler by supporting large audiences and giving users the ability to spread a message through online communities (Raacke \& Bonds-Raacke, 2008). Platforms such as Hi5, MySpace, and Friendster began before the boom of Facebook in 2007, however, they could not sustain themselves against the competition. Organizations that realized the potential of social media and strategized to use it to their advantage survived. As more and more organizations and individuals got on to social media, it evolved to what we know it today (Kalinin et al., 2020). The user who was predominantly a consumer with many sources of entertainment has now changed to a content creator who dictates the very content that is generated (Voorveld et al., 2018). This shift in behavior was invoked by the rise of social media platforms which have slowly morphed into personalized stages of communication (Van den Broeck et al., 2020).

The users whether a millennial, Gen X, Gen Y, or a baby boomer (Sinclair \& Grieve, 2017) all have different usage patterns. This evolution can be observed through the study of scholarly research articles published in journals across domains. Scholarly works in this area prove that there has been an increase in the research articles from 2007 to 2020 as observed on Scopus database. In the pursuit to study human behavior, researchers have delved into the areas of digital user motivations, content consumption, psychology, sociology, and computer user behavior to bring about a better understanding of the impact of the changes in the digital landscape. This study highlights the reasons for the growing popularity of different social media formats, the nature of the interaction between the user and the platform, the motivations behind usage, and the impact of consumer usage on the platform itself.

A Systematic literature review methodology is a good fit as it uses existing literature to answer to research questions qualitatively and can be used as the groundwork for more studies in the future (Greenhalgh \& Taylor, 1997). This systematic literature review is organized as follows a sequence starting with a detailed breakdown of the methodology used, the scope of the study, the process followed to gain insights followed by the methodological and thematic review. In the end, the limitations and directions for future research are mentioned.

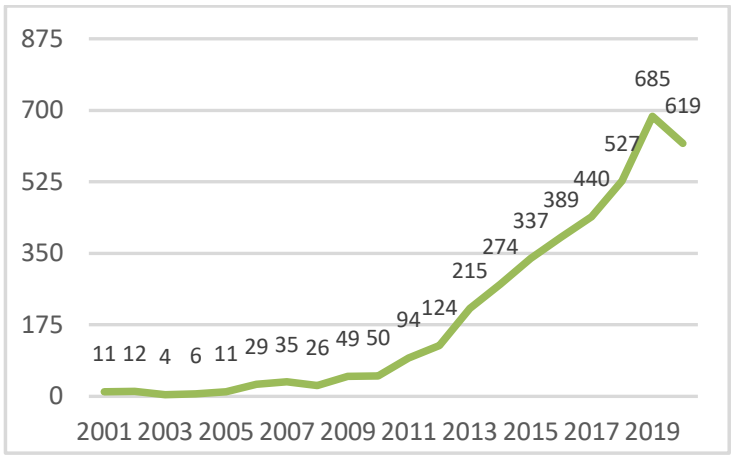

Figure 1. Number of articles on Social Media Usage on the Scopus Database as of October 24,2020

\section{SYSTEMATIC LITERATURE REVIEW METHODOLOGY}

A systematic literature review methodology gave this study a road map and faclilitated additional rigor to cover the breadth of work conducted towards understanding user behavior as a result of the social media evolution. As described by Fink (2005) in the book 'Conducting research literature reviews: From the internet to paper' - an independent systematic literature review is useful as there is a process followed to gather past literature and find trends as it clearly indicates the details of the exercise followed to conduct the review; 'comprehensive' as several sources are connected to bring together the database for the selected topic; and, is also 'reproducible' as the new knowledge base can be used in further probes.

A systematic literature review helps in extracting the most relevant data from a pool of research and can be used to identify trends. The review helps in investigating new ideas which could be at different ends of the discussion. This polarity is important to gauge the breadth of study within the scope of the topic itself. The methods employed in the study are the total of the following subsections explicating the scope of the systematic literature review, the techniques used to identify research, and the results generated through the systematic literature review methodology. 


\section{Scope - Systematic Literature Review}

The extent of this literature review can be defined by the restrictions imposed on the search criteria. The form of the search criteria was limited to journals only as these provide a rich source of peer-reviewed knowledge about the relevant subject matter. They are the sources of information which can be used as the basis for further study. In addition, this review does not include conference papers, book chapters, reviews, and editorials since these lack the rigour which journal articles go through for publication.

The systematic literature review was used as a means to gather data relating to consumer behavioral changes with the evolution of social media and the internet at large. Within the purview of content selection, the journal articles published in the field of computer science were excluded due predominance of technology related information. Finally, the journal articles were selected if they contained information related to the following research questions -

RQ1. What are the consumers motivations for using different social media platforms and how have these evolved over the years?

RQ2. How has content on these platforms evolved and what is its impact on passive and active user engagement?

RQ3. How have organizations harnessed social media to enhance their brand engagement?

\section{Identification of Relevant Literature}

The process of extracting, assessing, and identifying relevant literature was done in a single phase by the authors in October 2020. The feasibility of the study was tested by assessing the amount of research that has been done in the past two decades on the topic of study. This stage was crucial to find out if the systematic literature review can be conducted with reliable sources of data. Also, the authors confirmed that no such comprehensive review of literature was published in the last 7 years on this topic. Thus, the review began with identifying the most suitable keywords which support the area of research in the most-broad form.
The keywords used for the search include 'user behavior', 'social media', 'psychology', 'social engagement', 'sentiment analysis', 'social media platforms', 'Facebook', 'Twitter', 'online behavior', 'Web 2.0', 'usage behavior', 'media usage' and 'Internet landscape' as found on 8 research databases namely Scopus, Taylor and Francis, Emerald, JSTOR, Mendeley, Sage, Elsevier and Web of Science.

The aforementioned databases were suitable search hosts as the affiliate university of the authors provided access to these large bank of research studies by means of memberships. Furthermore, it was found that the databases have a sizable quantum of studies relating to the topic in the area of business, management, sociology, and psychology.

The systematic literature review was thus effective with 437 results (Figure 2) using keyword search as of Oct 24, 2020. This first phase examination following the keyword search was used to collect additional information about each journal article like author name(s), title of the research paper, year of publication, journal title, volume, and issue number, start and end page references, number of citations to date, document type, database source, and DOI numbers. The authors proceeded with coding the research papers to eliminate any duplicates. A total of 212 were found to be duplicates and were removed from the study.

The study was then limited to 225 articles remaining after elimination of duplicates. In the next step, the authors followed by reading the abstracts and examining the full texts of all the selected papers to decide whether to include them in the study. The articles were included if they answered any of the research questions mentioned in section 2.1 - Scope of Systematic Literature Review. The 225 articles were split amongst two groups of authors, each group containing two members. Each article in the sample was independently analyzed for reasonableness of the subject matter with respect to the topic and scope of the literature review. In case of any difference in opinions, the other group members were consulted. At this stage, another 164 records were eliminated due to a mismatch with the scope the research. Finally, a total of 61 papers were included in the methodological and thematic review. 
Results - Systematic Literature Review

By analyzing the year of publication of the final 61 research articles, it can be inferred that the bulk of the research conducted in this area has been done from 2007 to 2019 with a constant increase from 2007 and a sharp increase in the year 2019. While the rise in research in 2007 was due to the rise of Facebook, one of the first social networking platforms. Another steep rise has occurred in 2019 coinciding with a massive change in the way social media was designed and the expectations of consumers from social media. the COVID-19 worldwide lockdown (Naeem, 2021).

The increase in digital activity in the early months of 2020 led to media users seeking increased engagement, entertainment, and most of all, connection with the world. Another important observation is the increase in the amount of consumer behavioral studies in the fields of social sciences and psychology after the rise of social media within the last 2 years.

Table 1. Research Databases - search criterion

\begin{tabular}{|c|c|c|c|}
\hline Database & Scope and Search Criteria & $\begin{array}{l}\text { Date of } \\
\text { search }\end{array}$ & $\begin{array}{l}\text { Number } \\
\text { of items }\end{array}$ \\
\hline Mendeley & $\begin{array}{l}\text { Search - All journals, Item Type: Articles, Language: } \\
\text { English, Publication Date: } 2000-2020\end{array}$ & $20 / 10 / 2020$ & 64 \\
\hline $\begin{array}{l}\text { Web of } \\
\text { Science }\end{array}$ & $\begin{array}{l}\text { Search: Topic } \\
\text { Document type: Articles, Language: English }\end{array}$ & $20 / 10 / 2020$ & 43 \\
\hline Sage & $\begin{array}{l}\text { Search: Topic } \\
\text { Document Type: Article } \\
\text { Language: English } \\
\text { Publication Date: } 2000-2020\end{array}$ & $20 / 10 / 2020$ & 40 \\
\hline Elsevier & $\begin{array}{l}\text { Search: Abstract } \\
\text { Scholarly journals } \\
\text { Document type: Article, Language: English }\end{array}$ & $20 / 10 / 2020$ & 58 \\
\hline Emerald & $\begin{array}{l}\text { Advanced Search: Journal Articles, search terms: social } \\
\text { media and user behaviour, date range - 2000-2020 }\end{array}$ & $20 / 10 / 2020$ & 47 \\
\hline JSTOR & $\begin{array}{l}\text { Advanced Search - Keywords: social media and user } \\
\text { behaviour, Item Type: Articles, Language: English, } \\
\text { Publication Date: 2000-2020 }\end{array}$ & $20 / 10 / 2020$ & 55 \\
\hline $\begin{array}{l}\text { Taylor and } \\
\text { Francis }\end{array}$ & $\begin{array}{l}\text { Search: Abstract or author-supplied } \\
\text { abstract Scholarly (peer-reviewed) journals } \\
\text { Publication type: Academic journal } \\
\text { Document type: Article }\end{array}$ & $20 / 10 / 2020$ & 50 \\
\hline Scopus & $\begin{array}{l}\text { Search: All journals Abstract, keywords, and titles } \\
\text { Document type: Article Title and Review } \\
\text { article }\end{array}$ & $20 / 10 / 2020$ & 80 \\
\hline Total & & & 437 \\
\hline
\end{tabular}

Users expecting a seamless experience across multiple platforms led to social media companies fighting for the best in technology and user research. Certain formats were successful which promised authenticity and creativity compared to other platforms. This helped them to gain traction with consumers with a large attention deficit and a propensity to change quickly. The last five years have thus seen a large amount of this volatility in user engagement towards content consumption with a faster change throttled by

\section{METHODOLOGICAL REVIEW}

The methods used in this systematic literature review shed light on the kind of studies that have been done in the area of social media research pertaining to user behavior.

The study revealed the maximum amount of research in the total sample $(n=61)$ has been done using quantitative methods with 27 $(44.26 \%)$ articles reflective a methodological preference for quantitative research. 


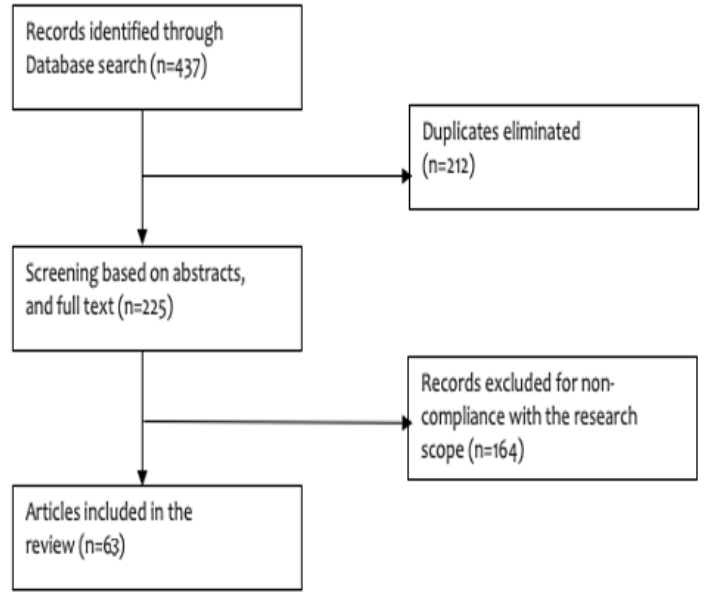

Figure 2. Flow chart depicting the methodological process used to identify literature pertaining to Social Media Usage Behaviour

\begin{tabular}{|l|c|c|}
\hline Methodology & Nos of Articles & Percentage \\
\hline Quantitative & 27 & 44.26 \\
\hline Qualitative & 10 & 16.39 \\
\hline Mixed & 13 & 21.32 \\
\hline Non-empirical & 11 & 18.03 \\
\hline \multicolumn{1}{|c|}{ Total } & $\mathbf{6 1}$ & $\mathbf{1 0 0 . 0 0}$ \\
\hline
\end{tabular}

Figure 3. Methodological Research Methods articles.

The qualitative research studies $(\mathrm{n}=10)$ were at $16.39 \%$. A reasonable number $(n=13,21.32 \%)$ of the sample articles used both surveys and interview techniques - mixed methods to gain information from users as well as to conduct an overall sentiment analysis in the market. With the substantial changes in the social media landscape, researchers have also used non-empirical methods to gathered insights by observing past and current research on social media usage behavior. Thus, $18.03 \%(n=11)$ of the sample pool of research articles were nonempirical in nature.

The use of quantitative and mixed methods to study social media is preferred as seen through the sample study pool of the aforementioned 61 articles. The benefit of using these methods over others is that the need for conclusive research can be met. Thus, quantitative data is used to employ mathematical models which provide real usable insights to the phenomena under study. Studies have also used non - empirical research methods to conceptualize various aspects of social media and also review etant literature from time to time.

\section{THEMATIC REVIEW}

The salient themes highlighted in this systematic literature review were found based on the research articles finally included in the study $(n=61)$. The research questions were used to identify relevant literature based on the abstracts and full texts of the articles.

The literature review revealed 16 papers towards relevant to consumer motivations, 8 papers towards the impact of format types, 13 papers toward changes in content, and 24 papers on the reverse impact of user behavior on the social media platforms.

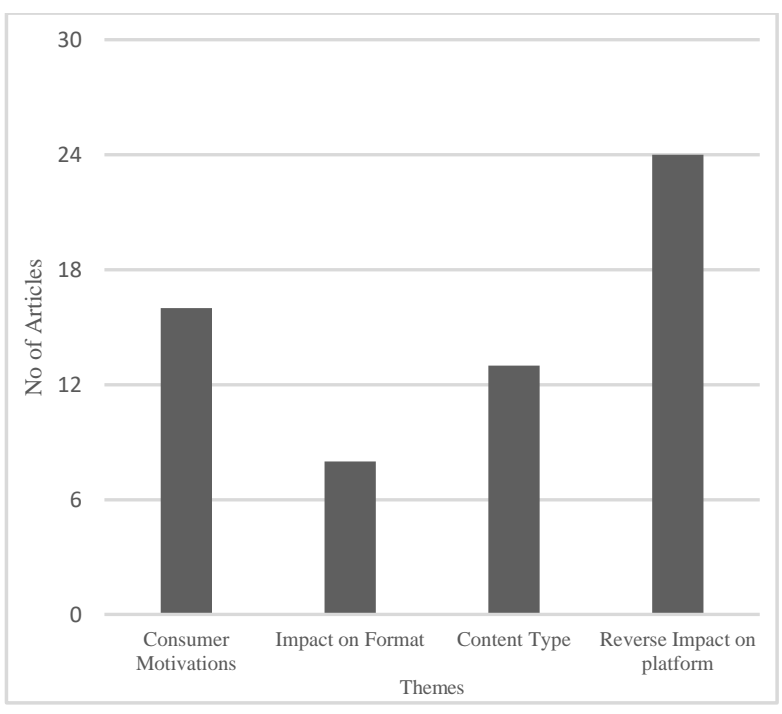

Figure 4. Division of themes within the sampled articles

\section{Consumer Motivations}

The first prominent theme that emerged was the motives that drive consumers/users to interact with social media platforms which were evident by studying the 16 articles included as a result of the systematic literature review. Social Media has gradually transformed the digital landscape (Duffett, 2017). Social Media in all its myriad forms has become a pivotal communication medium in the modern world. However, it is undeniably clear that at the crux of it all, consumers' motivations to explore new media drive usage and increased inclusion into our daily lives (Bolton et al., 2013; Zavattaro \& Brainard, 2019). The biggest advantage that social media provides its users is instantaneous access to information. With users constantly navigating a vast ocean of information, social media inevitably becomes a go-to source for an attention-deficit world. Moreover, several 
studies have indicated that social media has been able to build a community which helps people to connect at an emotional level (Ghatak \& Singh, 2019). The newfound medium of social connectedness (Waheed et al., 2017) has enabled users to collaborate and create through easy information exchanges. From the early days of social media, the internet has seen several different forms of platforms which satisfy different consumer needs. The possibility to use one's creativity has led to the rise of 'personal publics' (Trepte, 2015) who share similar ideas and visions and form an environment of beneficial dialogue. The ability to empower people (Fatima et al., 2015) through self-controlled channels makes social media a favorite destination for all those who seek to spread the message of social development.

To some users, social media platforms are a way of channeling their positive energy or boredom in their free time. It has been recorded by several studies that social media usage often leads to time-distortion (Brailovskaia et al., 2020). Lurking is often seen as a means of creating or interacting with content with no intention to help in the growth of the community (Engler \& Alpar, 2018). Thus, users who are focused on escapism may find themselves using social media platforms for long durations compared to those who don't. Additionally, social media can also be used as a conduit for escaping from a negative mindset as a mode of distraction.

Another common user motivation is the use of social media to seek a new experience. The last decade has seen a rise in new formats due to the quick redundancy of older platforms with respect to new consumer wants and needs. For instance, Facebook is a social networking platform, Twitter is a microblogging platform, YouTube enables users to share video content, Instagram is a photo-sharing platform, TikTok focuses on the snack video culture and Pinterest is a creative information mood board. Social media motivates users through a combination of emotional, cognitive, and social activations (Dolan et al., 2019). This in turn creates user behaviours of varying intensities such as lower passive (consumption), moderately active (contribution), and highly active (creation). The intensity of usage also depends upon the primary motivations of the user - Promotion focus with a benefit for oneself and Prevention focus with a perspective of the larger good. King and Weidong Xia (1997) advocated in their research on media choice, that selfinterest and efficiency orientation aspects are more powerful than rational motivation. This demonstrates that the motivation to choose a social media platform for daily use is governed by self-seeking factors and the need for gaining new experiences to learn (Brailovskaia \& Margraf, 2018; Spiliotopoulos \& Oakley, 2020).

Users expect that the investment made towards social media is worthwhile if the factors of social identity, group norms (Ellison et al., 2007), image, the value of the network, and expectations with respect to performance are met (Peters et al., 2013; Ruangkanjanases et al., 2020). Any social media platform that piques curiosity, enjoyment, and concentration (Aragoncillo et al., 2017) is chosen by the user to meet their information and emotional needs.

\section{Influence of Media Formats on Usage}

The review found 8 articles on the second theme as indicated by the research question. Social Media uses mobile-first (Au et al., 2015) and web-based technologies to generate a seamless user experience. The impact of user experience on the usage of the social media platform is crucial to ensure user engagement through time. The first social media networking site - Sixdegrees was created over two decades ago (Kietzmann et al., 2011). Over the years, these social netwrorking sites have evolved to keep up to the expectations of the users (Smith et al., 2012). Addiding new features and functionality to these sites calls for extensive research as against improvement to blog-based platforms which are easy to make and maintain. The design of a social media platform can creates a favourable environment for users to actively participate in an online setting. This could be in the form of likes, shares, comments, message posts, images which further drive the user activity on a platform and inform the design of the platform itself to make it more convenient for use (Vaca et al., 2014). Social media platforms are intangible experiences designed to engage users meaningfully. They could be created for varied purposes of collective engagement, blogs, content communities, social networking sites, online gaming, and social virtual world 
in order to provide the relevant ecosystems (Hogg et al., 2013). Designers need to study the usage as well as the devices that the users are connected to. The connection of data services on smartphones (Desmal, 2017) has led to an exponential increase in the capabilities offered by social media platforms. To illustrate by example, users on Facebook typically access the application through their mobile phones $(96 \%)$ as compared to their computers $(25 \%)$. On the other hand, Instagram users prefer the application because of the variety of features available in the mobile format. However, it must be noted that active participation is possible only when the users are less distracted such as when working on a computer which happens in a less disruptive environment as opposed to a mobile device. This implies that compared to Instagram, Facebook reels in more active participation with equal access available through the website and the mobile application (Shahbaznezhad et al., 2021).

The importance of site layout is another factor which affects passive and active engagement. Web data analytics (Abbas et al., 2019) enables organizations to track and reset the formats of the platforms to stay relevant with the times.

In addition, the legal architecture of the social media platform impacts usage safety. With the increasing concerns on privacy and the divergence in each platform, it is imperative that user behavior must be monitored and the nature of the platform stay lucrative in the minds of the users.

\section{Content-Type}

The intention to use a social media platform is greatly impacted by the type of content that the platform supports (Brandão et al., 2019) as seen in the 13 articles in this review. The content consumption patterns of users can be categorized under the following heads of social interaction, archiving, self-expression, escapism, and peeking (Lee et al., 2015). Content which enables social interaction is used to engage with people, create a likeminded network, gain updates on close friends and family, and open discussions on happenings across the globe. The archiving content is fuelled by nostalgia and is typically used as a private online space to hold old photos, videos (Törhönen et al., 2019), and conversations. The revolution of online filters greatly enabled archiving as a popular practice on the internet. Besides archiving, social media content is always directed at self-expression to share personal experiences with one's voice. Self-expression to some may mean content which is meant to issue an update or to others to show off their lives within their community. The popularity of social media has grown across the world due to its ability to create an escape from the real world. Such content plays into the aspirations of the users and becomes a source of motivation to engage more. Escapist content is like meditation to all those who consume it in their free time. The most common type of content is generated to fill the online space for browsing. It enables knowledge sharing (Fotis, 2015) among people who are motivated by similar ideas.

Based on the size and distribution power of the social media channel, the content should have features which are high in quality, encompass the relevant domains as per the user demands, reflect the emotions and tone of voice that users can relate to, and be able to fulfill the demand in terms of volume (Peters et al., 2013). These aspects of content generation lead to the creation of intellectual, social, and cultural value to the users. Content consumed must relay a message to the public which holds meaning in terms of creativity or culture. Further, value can be created within an online social media community by using the content as a powerful resource for social good.

Content consumption has changed over the years. Traditional sources of content consumption such as newspapers articles (Joanna \& Zuzanna, 2020; Robinson et al., 2000) are at a disadvantage with the rise of social media as active internet users (ShaneSimpson et al., 2018) are more social on new digital platforms due to the variety and strength of the content itself. The systematic literature review shed light on studies which further pointed out that younger people are heavier users than older people (Holt et al., 2013). The younger users employ social media as news (Nielsen \& Schrøder, 2014) as well as an entertainment source.

Increased use of social media content consumption is known to have negative impacts on the users in the long term. Addictive behaviors coupled with long hours 
of usage leads to narcissism and self-esteem issues in users (Akubugwo \& Burke, 2013; Andreassen et al., 2017; Hou et al., 2019).

\section{Inverse impact on social media platforms}

How users share information on social media changes the way social media platforms behave. User engagement is monitored to understand how to design social media platforms to satisfy their needs and to keep up with the demands on digital as observed in the 24 articles studied. With the switch to content creation, users dictate the product and services (Kapoor et al., 2018), the activities, and the media that floats on social media platforms (Ek Styvén \& Foster, 2018). Passive engagement (Klein et al., 2020) by the user points to a user experience which is more laidback and supports browsing. Active participation relates to a user experience which is high on engagement with several opportunities for creating messages and holding conversations on topics of mutual interests. For instance, the typical social media user can spend over 20 minutes on a single site, and over two-thirds of the users login into the platforms at least once a day (Ellison et al., 2007). The user behaviour thus lends to the type of content generated by third parties such as brands (Lee et al., 2018), social organizations, and influencers as being informational, experiential, and transactional.

Likers or commenters on social media can change the likeability of a brand (Chang et al., 2019; Kong et al., 2020). This reverse pressure on social media is exerted by the user's attitudes on advertising. The availability of a product or service of choice on the platforms where users spend a large amount of time is a vital driver for creating an ecosystem within social media which is conducive to such behavior (Razavi, 2020). Brands have used social media to connect with their consumers and relay their visions to the consumers to increase relatability (Jain et al., 2020) and consumer agency (Badenes-Rocha et al., 2019; De Domenico \& Altmann, 2020; Stojanovic et al., 2018). Research has shown that users are looking for content platforms which are affiliated with their beliefs and lifestyles, thus, brands use storytelling (Malthouse et al., 2013) as a way to create content instead of information sharing only.
The bottom line is that users can change the economic strength of a social media platform. With the aim to create a community for the users, social media designers should be cognizant of usage themes (Kaplan \& Haenlein, 2010) and keep track of what ensures the continuity of the platform. Facebook began as a closed community social media service and switched to the public to further amplify common interests and move beyond geography (Bigne et al., 2020; Frost \& Rickwood, 2017; Mauri et al., 2011). According to Ruangkanjanases et al. (2020, p. 12):

\begin{abstract}
"In addition, social media communities should develop towards the network model, focus on relationship management, expand any small regional networks of heterogeneous members, increase the links between members, and thus stabilize the composition of members and enhance the user base. Such sites should also provide updated personal information, encourage members to interact, establish member files, and other functions."
\end{abstract}

Therefore, the power to communicate lies in the hands of the users of social media platforms as based on their digital decisions, brands can profile their needs and provide services in accordance with those needs (OseiFrimpong et al., 2019). The more involved a user is with the brand on social media, the higher the impact of its presence on more people. Several industries have used social media as a source of information on their prospective consumers. For instance, the travel industry (Aldao \& Mihalic, 2020; Javed et al., 2020) has tapped social media as the central destination for users to post about their travel experiences and aspirations. This data derived directly from the users helps brands within the travel industry, design lucrative offers in terms of products and services in real-time. How users interact with a platform information types, purchase information, and aspirational visits - indicates the likelihood of brand loyalty.

\section{LIMITATIONS}

The limitations of this study are related to the methodology of Systematic Literature Review employed for this research. Although this methodology is most suitable to bring together exant literature on any area of study, some limitations are unavoidable. Since Systematic Literature Review methodology starts with 
identification of keywords, missing inclusion of relevant keywords can lead to exclusion of relevant content from the review. Another important limitation of this methodology is the risk of the author's bias while selecting research papers from the databases. Since the papers in the second phase were picked solely based on the abstract, the likelihood of an innate bias is amplified. Also, to ensure rigour in the study, the search for relevant literature for this study was conducted on 8 different databases. As a result, massive data was accessed for further qualitatively analysis for final inclusion of articles in the sample. Strict protocol was followed for the same which may have lead to omission of some articles with relevant information which may be indirectly related to the topic. This drawback is especially relevant for broad areas like social media. Extensive country specific or industry specific research on social media would have narrowed the focus of this research. Hence the researchers used their judgement while including articles to ensure that the breadth of this study is not compromised with excessesive context specific research articles. The above-mentioned limitations are inherent to this form of research study as has been found in past research where Systematic Literature Review methodology was employed (Bhimani et al., 2019).

\section{Directions for Future use}

This Systematic Literature Review can be used to augment future studies which seek to realize the impact social media has on its users. As observed, the study revealed an exponential increase in this scope of research due to several environmental factors. This has been successfully documented through research articles which use empirical and quantitative research methodologies to elucidate the trends within the social media landscape. However, it can be observed that for a field of study focusing on human behavior, there is a lack of qualitative research which identifies the true motivations behind social media consumption amongst users of different ages, geographies, and cultures.

Thematically, the systematic literature review divulged answers to the research questions which can be propelled for further use. Several factors motivate consumers to use a social media platform, however, this study is in no way exhaustive, and therefore, more research needs to be conducted to identify the changing needs of the users. The position social media holds in society has changed drastically from users understanding its true strength to the realization of its evasiveness in our daily lives. The ability to provide creative platforms for users has led social media platforms to invest heavily in design incentives. The rise of usergenerated content has intrigued scholars and a large amount of research has been done to quantify the behavior which motivates users to create and share content. From the introduction of features to like and comment to the feature of sharing snack videos, a lot has transpired to popularize a social media platform.

Furthermore, content consumption has changed phenomenally. There are many social media platforms which have become one-stop destinations to gain and share information. This has led to the decease of usage of traditional media as they are unable to cater to the deficit attention spans of users today. Many studies have associated this change in consumption with prominent trends in the market.

In some cases, it has been observed that the user dictates the kind of services that a social media platform should offer to its audiences. This power shift has impacted organizations that utilizing social media platforms to find and engage the users. The quantum of this change can be noted by the amount of research conducted on factors affecting brand user engagement through social media. This systematic literature review can be used as the backbone for studying strategies that brands can use to create opportunities for an extensive user reach.

\section{CONCLUSION}

The aim of the paper was to understand the impact of social media on user behaviour. Given the vast reach of the topic through multiple disciplines, it was challenging to include all factors which influence this study. Through the systematic literature review methodology, we narrowed down to 61 relevant articles which were from multiple areas of study such as sociology, psychology, business, and management. We found that there is a need for a thorough qualitative study which includes a database that scrutinizes user behaviour on digital platforms. 
Based on our research, we can conclude that consumers show dependency on social media platforms for their daily lives for several emotional and transactional reasons. This impacts how social media platforms are designed using favorable devices and technology. In addition, content is central to worthwhile user engagement and has become the springboard for third parties to create experiences that their consumers truly want.

No potential conflict of interest was reported by the authors.

\section{REFERENCES}

Abbas, J., Aman, J., Nurunnabi, M., \& Bano, S. (2019). The impact of social media on learning behavior for sustainable education: Evidence of students from selected universities in Pakistan. Sustainability (Switzerland), 11(6), 1-23. https://doi.org/10.3390/su11061683

Akubugwo, I., \& Burke, M. (2013). Influence of social media on social behaviour of post graduate students. A case study of. IOSR Journal of Research $\mathcal{E}$ Method in Education, 3(6), 2320-7388. www.iosrjournals.org

Aldao, C., \& Mihalic, T. A. (2020). New frontiers in travel motivation and social media: The case of Longyearbyen, the High Arctic. Sustainability (Switzerland), 12(15), 1-19. https://doi.org/10.3390/ SU12155905

Andreassen, C., Pallese, S., \& D. Griffiths, M. (2017). Addictive use of social media, narcissism, and self-esteem. Addictive Behaviors, 64, 287-293. http://irep.ntu.ac. uk/id/eprint/27358/1/PubSub5118_Grif fiths.pdf

Aragoncillo, L., \& Orus, C. (2018). Impulse buying behaviour: an online-offline comparative and the impact of social media. Spanish Journal of Marketing - ESIC, 22(1), 42-62. doi:10.1108/sjme-03-2018007

Au, M., Lam, J., \& Chan, R. (2015). Social media education: Barriers and critical issues. Communications in Computer and Information Science, 494, 199-205. https://doi.org/10.1007/978-3-66246158-7_20

Badenes-Rocha, A., Ruiz-Mafé, C., \& Bigné, E. (2019). Engaging customers through user- and company-generated content on CSR. In Spanish Journal of Marketing - ESIC (Vol. 23, Issue 3). https://doi.org/10.1108/ SJME-09-2018-0043

Bhimani, H., Mention, A. L., \& Barlatier, P. J. (2019). Social media and innovation: A systematic literature review and future research directions. Technological Forecasting and Social Change, 144(August), 251-269. https://doi.org/ 10.1016/j.techfore.2018.10.007

Bigne, E., Andreu, L., Perez, C., \& Ruiz, C. (2020). Brand love is all around: loyalty behaviour, active and passive social media users. Current Issues in Tourism, 23(13), 1613-1630. https://doi.org/10. 1080/13683500.2019.1631760

Bolton, R. N., Parasuraman, A., Hoefnagels, A., Migchels, N., Kabadayi, S., Gruber, T., Loureiro, Y. K., \& Solnet, D. (2013). Understanding Generation $Y$ and their use of social media: A review and research agenda. Journal of Service Management, 24(3), 245-267. https://doi. org/10.1108/09564231311326987

Brailovskaia, J., \& Margraf, J. (2018). What does media use reveal about personality and mental health? An exploratory investigation among German students. PLoS ONE, 13(1), 1-16. https://doi.org /10.1371/journal.pone.0191810

Brailovskaia, J., Schillack, H., \& Margraf, J. (2020). Tell me why are you using social media (SM)! Relationship between reasons for use of SM, SM flow, daily stress, depression, anxiety, and addictive SM use - An exploratory investigation of young adults in Germany. Computers in Human Behavior, 113(July), 106511. https://doi.org/10.1016/j.chb.2020.10651 1

Brandão, A., Pinho, E., \& Rodrigues, P. (2019). Antecedents and consequences of luxury brand engagement in social media. Spanish Journal of Marketing - ESIC, 23(2), 163-183. https://doi.org/10.1108/SJME11-2018-0052

Chang, Y., Li, Y., Yan, J., \& Kumar, V. (2019). Getting more likes: the impact of narrative person and brand image on customer-brand interactions. Journal of the Academy of Marketing Science, 47(6), 1027- 
1045. https://doi.org/10.1007/s11747-1900632-2

De Domenico, M., \& Altmann, E. G. (2020). Unraveling the Origin of Social Bursts in Collective Attention. Scientific Reports, 10(1), 1-9. https://doi.org/10.1038/ s41598-020-61523-z

Dolan, R., Conduit, J., Frethey-Bentham, C., Fahy, J., \& Goodman, S. (2019). Social media engagement behavior: A framework for engaging customers through social media content. European Journal of Marketing, 53(10), 2213-2243. https://doi.org/10.1108/EJM-03-20170182

Duffett, R. G. (2017). Influence of social media marketing communications on young consumers' attitudes. Young Consumers, 18(1), 19-39. https://doi.org/10.1108/ YC-07-2016-00622

Ek Styvén, M., \& Foster, T. (2018). Who am I if you can't see me? The "self" of young travellers as driver of eWOM in social media. Journal of Tourism Futures, 4(1), 8092. https://doi.org/10.1108/JTF-12-20170057

Ellison, N. B., Steinfield, C., \& Lampe, C. (2007). The benefits of facebook "friends:" Social capital and college students' use of online social network sites. Journal of Computer-Mediated Communication, 12(4), 1143-1168. https://doi.org/10.1111/j. 1083-6101.2007.00367.x

Engler, T. H., \& Alpar, P. (2018). Contribution and consumption of content in enterprise social media. Information Systems Management, 35(1), 2-14. https://doi.org/ 10.1080/10580530.2017.1416935

Fatima, S., Manzoor, U., Zafar, B., \& Balubaid, M. (2015). Analyzing the Impact of Social Media on Users.

Fotis, J. N. (2015). The use of social media and its impacts on consumer behaviour: the context of holiday travel. The Use of Socialmedia and Its Impacts on Consumer Behaviour: The Context of Holiday Travel, May, 1-405.

Frost, R. L., \& Rickwood, D. J. (2017). A systematic review of the mental health outcomes associated with Facebook use. Computers in Human Behavior, 76, 576-600. https://doi.org/10.1016/j.chb.2017.08.00 1

Ghatak, S., \& Singh, S. (2019). Examining Maslow's Hierarchy Need Theory in the Social Media Adoption. FIIB Business Review, 8(4), 292-302. https://doi.org/ $10.1177 / 2319714519882830$

Greenhalgh, T., \& Taylor, R. (1997). How to read a paper: Papers that go beyond numbers (qualitative research). British Medical Journal, 315(7110), 740-743. https://doi.org/10.1136/bmj.315.7110.74 0

Hogg, T., Lerman, K., \& Smith, L. M. (2013). Stochastic Models Predict User Behavior in Social Media. July 2014. http://arxiv.org/abs/1308.2705

Holt, K., Shehata, A., Strömbäck, J., \& Ljungberg, E. (2013). Age and the effects of news media attention and social media use on political interest and participation: Do social media function as leveller? European Journal of Communication, 28(1), 19-34. 0267323112465369 https://doi.org/10.1177/

Hou, Y., Xiong, D., Jiang, T., Song, L., \& Wang, Q. (2019). Social media addiction: Its impact, mediation, and intervention. Cyberpsychology, 13(1). https://doi.org/ 10.5817/CP2019-1-4

Jaafar Desmal, A. (2017). The impact of using social media and internet on academic performance case study Bahrain Universities. ICST Transactions on Scalable Information Systems, 4(13), 152748. https://doi.org/10.4108/eai.28-62017.152748

Jain, V. K., Gupta, A., Tyagi, V., \& Verma, H. (2020). Social media and green consumption behavior of millennials. Journal of Content, Community and Communication, 10(6), 221-230. https://doi.org/10.31620/JCCC.06.20/16

Javed, M., Tučková, Z., \& Jibril, A. B. (2020). The role of social media on tourists' behavior: An empirical analysis of millennials from the Czech Republic. Sustainability (Switzerland), 12(18). https://doi.org/10.3390/su12187735

Joanna, B., \& Zuzanna, K. (2020). The impact of social media on managing the image of 
the Polish national football team. Physical Culture and Sport, Studies and Research, 87(1), 46-55. https://doi.org/10.2478/ pcssr-2020-0018

Kalinin, A., Vaganov, D., \& Bochenina, K. (2020). Discovering patterns of customer financial behavior using social media data. Social Network Analysis and Mining, 10(1), 1-14. https://doi.org/10.1007/ s13278-020-00690-3

Kaplan, A. M., \& Haenlein, M. (2010). Users of the world, unite! The challenges and opportunities of Social Media. Business Horizons, 53(1), 59-68. https://doi.org/10. 1016/j.bushor.2009.09.003

Kapoor, K. K., Tamilmani, K., Rana, N. P., Patil, P., Dwivedi, Y. K., \& Nerur, S. (2018). Advances in Social Media Research: Past, Present and Future. Information Systems Frontiers, 20(3), 531558. https://doi.org/10.1007/s10796-0179810-y

Kietzmann, J. H., Hermkens, K., McCarthy, I. P., \& Silvestre, B. S. (2011). Social media? Get serious! Understanding the functional building blocks of social media. Business Horizons, 54(3), 241-251. https://doi.org/ 10.1016/j.bushor.2011.01.005

King, R. C., \& Xia, W. (1997). Media appropriateness: Effects of experience on communication media choice. Decision Sciences, 28(4), 877-910. https://doi.org/ 10.1111/j.1540-5915.1997.tb01335.x

Klein, J. F., Zhang, Y., Falk, T., Aspara, J., \& Luo, X. (2020). Customer journey analyses in digital media: exploring the impact of cross-media exposure on customers' purchase decisions. Journal of Service Management, 31(3), 489-508. https://doi. org/10.1108/JOSM-11-2018-0360

Kong, Q., Mao, W., Chen, G., \& Zeng, D. (2020). Exploring Trends and Patterns of Popularity Stage Evolution in Social Media. IEEE Transactions on Systems, Man, and Cybernetics: Systems, 50(10), 38173827. https://doi.org/10.1109/TSMC. 2018.2855806

Lee, D., Hosanagar, K., \& Nair, H. S. (2018). Advertising Content and Consumer Engagement on Social Media: Evidence from Facebook. Management Science Published online in Articles in Advance.
Management Science, January, 1-27.

Lee, E., Lee, J. A., Moon, J. H., \& Sung, Y. (2015). Pictures Speak Louder than Words: Motivations for Using Instagram. Cyberpsychology, Behavior, and Social Networking, 18(9), 552-556. https://doi.org/10.1089/cyber.2015.0157

Malthouse, E. C., Haenlein, M., Skiera, B., Wege, E., \& Zhang, M. (2013). Managing customer relationships in the social media era: Introducing the social CRM house. Journal of Interactive Marketing, 27(4), 270280.https://doi.org/10.1016/j.intmar.201 3.09 .008

Mauri, M., Cipresso, P., Balgera, A., Villamira, M., \& Riva, G. (2011). Why is Facebook so successful? Psychophysiological measures describe a core flow state while using Facebook. Cyberpsychology, Behavior, and Social Networking, 14(12), 723-731. https://doi.org/10.1089/cyber.2010.0377

Naeem, M. (2021). Do social media platforms develop consumer panic buying during the fear of Covid-19 pandemic. Journal of Retailing and Consumer Services, 58(July 2020), 102226. https://doi.org/10.1016/ j.jretconser.2020.102226

Nielsen, R. K., \& Schrøder, K. C. (2014). The Relative Importance of Social Media for Accessing, Finding, and Engaging with News: An eight-country cross-media comparison. Digital Journalism, 2(4), 472489. https://doi.org/10.1080/21670811. 2013.872420

Osei-Frimpong, K., McLean, G., \& Famiyeh, S. (2019). Social media brand engagement practices: Examining the role of consumer brand knowledge, social pressure, social relatedness, and brand trust. Information Technology and People, 33(4), 1235-1254. https://doi.org/10.1108/ITP-05-20180220

Peters, K., Chen, Y., Kaplan, A. M., Ognibeni, B., \& Pauwels, K. (2013). Social media metrics - A framework and guidelines for managing social media. Journal of Interactive Marketing, 27(4), 281-298. https://doi.org/10.1016/j.intmar.2013.09. 007

Raacke, J., \& Bonds-Raacke, J. (2008). MySpace and facebook: Applying the uses and gratifications theory to exploring friend- 
networking sites. Cyberpsychology and Behavior, 11(2), 169-174. https://doi.org/ $10.1089 /$ cpb.2007.0056

Razavi, R. (2020). Personality segmentation of users through mining their mobile usage patterns. International Journal of Human Computer Studies, 143, 102470. https:// doi.org/10.1016/j.ijhcs.2020.102470

Robinson, J. P., Kestnbaum, M., \& Alvarez, A. (2000). Among Internet Users. Social Science, 18(4).

Ruangkanjanases, A., Hsu, S. L., Wu, Y. J., Chen, S. C., \& Chang, J. Y. (2020). What drives continuance intention towards social media? Social influence and identity perspectives. Sustainability (Switzerland), 12(17), 1-15. https://doi. org/10.3390/su12177081

Shahbaznezhad, H., Dolan, R., \& Rashidirad, M. (2021). The Role of Social Media Content Format and Platform in Users' Engagement Behavior. Journal of Interactive Marketing, 53, 47-65. https:// doi.org/10.1016/j.intmar.2020.05.001

Shane-Simpson, C., Manago, A., Gaggi, N., \& Gillespie-Lynch, K. (2018). Why do college students prefer Facebook, Twitter, or Instagram? Site affordances, tensions between privacy and self-expression, and implications for social capital. Computers in Human Behavior, 86, 276-288. https:/ / doi.org/10.1016/j.chb.2018.04.041

Sinclair, T. J., \& Grieve, R. (2017). Facebook as a source of social connectedness in older adults. Computers in Human Behavior, 66, 363-369. https://doi.org/10.1016/j.chb. 2016.10.003

Smith, A. N., Fischer, E., \& Yongjian, C. (2012). How Does Brand-related User-generated Content Differ across YouTube, Facebook, and Twitter? Journal of Interactive Marketing, 26(2), 102-113. https://doi. org/10.1016/j.intmar.2012.01.002

Spiliotopoulos, T., \& Oakley, I. (2020). An exploration of motives and behavior across Facebook and Twitter. Journal of Systems and Information Technology, 22(2), 201-222. https://doi.org/10.1108/JSIT12-2019-0258

Stojanovic, I., Andreu, L., \& Curras-Perez, R. (2018). Effects of the intensity of use of social media on brand equity: An empirical study in a tourist destination. European Journal of Management and Business Economics, 27(1), 83-100. https:/ / doi.org/10.1108/EJMBE-11-20170049

Törhönen, M., Sjöblom, M., Hassan, L., \& Hamari, J. (2019). Fame and fortune, or just fun? A study on why people create content on video platforms. Internet Research, 30(1), 165-190. https://doi.org/ 10.1108/INTR-06-2018-0270

Trepte, S. (2015). Social Media, Privacy, and Self-Disclosure: The Turbulence Caused by Social Media's Affordances. Social Media and Society, 1(1). https://doi.org/ $10.1177 / 2056305115578681$

Vaca Ruiz, C., Aiello, L. M., \& Jaimes, A. (2014). Modeling dynamics of attention in social media with user efficiency. EPJ Data Science, 3(1), 1-15. https://doi.org/10.1140/epjds30

Van den Broeck, E., Poels, K., \& Walrave, M. (2020). How do users evaluate personalized Facebook advertising? An analysis of consumer- and advertiser controlled factors. Qualitative Market Research, 23(2), 309-327. https://doi.org/ 10.1108/QMR-10-2018-0125

Voorveld, H. A. M., van Noort, G., Muntinga, D. G., \& Bronner, F. (2018). Engagement with Social Media and Social Media Advertising: The Differentiating Role of Platform Type. Journal of Advertising, 47(1), 38-54. $\quad$ https://doi.org/ 10.1080/00913367.2017.1405754

Waheed, H., Anjum, M., Rehman, M., \& Khawaja, A. (2017). Investigation of user behavior on social networking sites. PLoS ONE, 12(2), 1-19. https://doi.org/ 10.1371/journal.pone.0169693

Zavattaro, S. M., \& Brainard, L. A. (2019). Social media as micro-encounters: Millennial preferences as moderators of digital public value creation. International Journal of Public Sector Management, 32(5), 534-552. https://doi.org/10.1108/IJPSM02-2018-0059 


\section{APPENDIX -}

\section{Databases Reviewed for the Systematic} Literature Review

- Elsevier - https://www.elsevier.com/enin Elsevier is a modern publishing industry that has developed from a small classical scholarship publishing house in the Netherlands to a multinational online publishing company with more than 20,000 global products in the fields of education, technical science, and healthcare.

- Emerald https:/ / www.emerald.com/insight/ Emerald contains over 500,000-researchers from more than 130 countries/regions, 30 million yearly downloads, and 109 million visitors from all over the world making it a leading publisher in the digital forum.

- Taylor and Francis https://taylorandfrancis.com/

Taylor \& Francis Group is an international company publishing books and academic journals, collaborates with world-class writers. Together they have published in all the fields of humanities, social sciences, behavioural sciences, science, technology, and medicine. Its contents include more than 2,700 periodicals and more than 5,000 new books each year.

- Web of Science

http://apps.webofknowledge.com/

Web of Science is a platform that offers numerous databases that provide extensive citation data for several different disciplines with subscription-based access. More than 100 years of abstracts, more than 90 million documents, and 5,300 publications in social sciences spanning 55 disciplines are included.
- Mendeley

https://www.mendeley.com/search/

Mendeley is a London based company that provides academic researchers with products and services. It is famous for its reference manager, which is used to manage and share research papers and to generate scholarly paper bibliographies. It easily Imports articles quickly from other research-based software's.

- JSTOR - https://www.jstor.org/ JSTOR is a subsidiary of ITHAKA, a notfor-profit organization that also includes multiple other platforms specializing in lowering the cost of education across the globe. JSTOR currently provides over 12 million scholarly journal articles, 85,000 books, and 2 million primary source papers in over 70 different disciplines. They are known to decrease prices and maximize shelf space, offer free and lowcost access as well as scholarships for independent academics, and help publishers attract new markets and retain their material for future generations.

- Scopus - https://www.scopus.com/ Scopus is a subsidiary of Elsevier's abstract and citation database which consists of peer-reviewed papers. It is famous for being global oriented and includes multi-discipline subjects for all its different user base,

- Sage Publishing - https://us. sagepub.com/en-us/nam/home

SAGE is a worldwide scholarly publisher of books, journals and a growing suite of products and services for libraries. Their emphasis is on publishing impactful research and allowing rigorous methods for research. Every year, Sage publishes over 1,000 journals and 900 new books worldwide, as well as library products and services, including archives, data, case studies and video. 